\title{
CAMPOS, Pedro Henrique Pedreira; BRANDÃO, Rafael Vaz da Motta. Os Donos do Capital: A trajetória das principais famílias empresariais do capitalismo brasileiro
}

\author{
Glória Estevinho ${ }^{1}$
}

- Enviado em 13/04/2018.

- Aprovado em 10/06/2018.

A proposta dos autores é, a partir de diferentes matrizes conceituais, resgatar a formação filosófica, as relações econômicas, os vínculos com o Estado, as relações com os capitais estrangeiros, a ideologia, a atuação política, o consenso e as contradições internas de alguns renomados grupos familiares de capitalistas brasileiros. Desse modo, o foco de analise é a elite brasileira que atuou desde o Brasil imperial até os dias de hoje, numa análise minuciosa, por parte dos pesquisadores, fornece subsídios para se pensar a construção de certos capitais que identificam uma classe dominante e que dão o tom de como as coisas funcionam no país. O livro está dividido em 10 grandes sobrenomes que atuaram como os donos do capital na história do Brasil, descrita desde o império até a era Sarney. Esse exame minucioso resgata a trajetória de Irineu Evangelista de Souza passando por vários empreendimentos que imprimem na história uma marca na forma de alguns sobrenomes como: Guinle, Simonsen, Klabin, Gerdau, Marinho, Sarney e Odebrecht, entre outros, de tal sorte que além de mapear o Brasil por regiões de concentração de capital demonstra a ascensão e consolidação e, por vezes, o declínio do poder econômico desses núcleos familiares.

Muitos mitos envolvem o imaginário social quando o assunto é riqueza, poder, ideologia, enfim, o primeiro capítulo do livro vai abordar essa dimensão no que se refere ao abolicionismo. Irineu Evangelista de Souza é o Visconde de Mauá, cujo mito de abolicionista cai por terra a partir do escrutínio realizado pela autora. $\mathrm{O}$ artigo se propõe a mostrar as relações comerciais dos ingleses e sua postura, ou a falta dela,

\footnotetext{
${ }^{1}$ Graduada em Ciências Sociais pela Universidade Federal do Paraná. Especialização em Sociologia Política pela Universidade Federal do Paraná. Atualmente atua como docente compondo o Quadro Próprio do Magistério no Governo do Estado do Paraná. Mestranda Sociologia Política. Linha de Pesquisa: Cidadania e Estado, Eixo Temático: Instituição e Poder, UFPR 2018. Endereço eletrônico: geg@seed.pr.gov.br
} 
diante de uma economia agroexportadora e escravista, como é o caso do Brasil da época. Nesse contexto, é apresentado ao leitor o surgimento de um homem de negócios que aliado a trilogia: política, capital e Estado faz nascer o mito abolicionista. Esse artigo apresenta-se dividido em dois momentos de reflexão, o primeiro acima exposto e, num segundo momento, dados documentais registrados em atas que confirmam a discordância entre o discurso e a prática do Visconde no processo de instalação e desenvolvimento do Estaleiro e Fundição de Ponta d'Areia, de sua propriedade. Os mitos criados durante o império esconderam, nesse caso, oportunismos, negociatas e privilégios. Um empreendimento desta envergadura envolvia uma enorme quantia em réis que o Visconde não dispunha, então alguns acordos são firmados para realizar o intento. Essa possibilidade se concretiza em função de uma relação pessoal com agentes do império, simpáticos com a causa da instalação da fundição. No bojo o que temos é o dinheiro público financiando obras privadas. Esse modus operandi despreza as (des)condições de trabalho e sucumbi as questões próprias da escravidão do Brasil ${ }^{2}$. Nessa época, em termos econômicos, há uma aproximação com o capital estrangeiro sendo uma das exigências o fim da escravidão ${ }^{3}$, internamente, entre os donos de terras essa questão não era unânime e andavam juntos trabalho escravo e assalariado A trajetória do Visconde de Mauá vai da sua condição de órfão a self made man de tal sorte que aos 27 anos era diretor da firma Carruthers do Rio de Janeiro de onde o contato com os ingleses era fecundo, quer para atender aos seus objetivos comercias por conta da empresa que dirigia, quer para alçar novos voos junto ao Brasil imperial. Interessante notar que a influência inglesa sobre os assuntos do Brasil datam da vinda da família real, perpetuando-se em vários momentos da história nacional. A referência utilizada vai de Caio Prado Júnior a José Murilo de Carvalho pontuando as atitudes que reforçam nas ações da burguesia o Estado como extensão de recursos que financiam interesses do capital particular. Dentro da ideia de modernização vislumbrada por Mauá, e de influência inglesa, estava sim o crescimento e a modernização do país, porém, de

\footnotetext{
${ }^{2}$ Ora se o quadro apresentado ao leitor é o de um Brasil agrícola e de mão de obra escrava e, ainda, sendo o Visconde de Mauá proprietário de um empreendimento, da envergadura de Ponta d’areia, que dispõe de trabalho escravo, como pode ser abolicionista? É desse modo que a autora o desmistifica. Essa análise é proposta na página 49 onde analisa uma tabela que apresenta a quantidade de trabalho escravo em detrimento ao trabalho livre na construção de Ponta d`areia (1846-1962)

${ }^{3}$ A nível mundial, do ponto de vista das condições de trabalho, as exigências para efetivar negociações com o Brasil era a do progressivo combate a escravidão. A lei brasileira nasce por força dessas condições de negociação impostas pelos ingleses de modo que em 04/09/1850 nasce uma nova lei.
} 
outro lado, um projeto para a continuidade da exploração e da manutenção da escravidão mas com fundamental financiamento público, nas palavras da autora:

\footnotetext{
Empresas como o Estaleiro e Fundição de Ponta d'Areia se enquadravam no ramo das atividades indiretamente subordinadas ao mesmo Estado, na medida em que forneciam suporte àquelas atividades de transporte, serviços urbanos e de crédito..
}

Sendo a economia imperial agrário exportadora a fala do Visconde reforçava a cada momento, junto ao governo, a importância das notáveis contribuições advindas do estaleiro e da fundição. Não assumindo postura radical Visconde de Mauá mantinha uma boa imagem perante ao governo, garantindo financiamento e continuidade de seus projetos e adotando mão de obra escrava na execução dos mesmos. Sendo um homem de sua época se articula entre empreendedorismo e ideologia de modo a ocultar sua verdadeira face escravista. Ganha destaque na empresa com interesse de avançar economicamente, mas dá, ao atento leitor, o desenho de como as coisas funcionam ao revelar por suas ações uma apropriação do aparelho de Estado. Assim, o texto atenta para o fato de como no Brasil imperial os ricos aumentavam suas fortunas e mantinham privilégios às custas de açoites desnaturalizando a figura dos "homens bons".

O leitor é convidado, no segundo capítulo, a desfrutar de uma história de riqueza, poder e glamour, a partir do sobrenome Guinle onde capitais são construídos e se consolidam valores de classe para si. A importância da família está no precursor Eduardo Palassim Guinle e Cândido Gaffrée, sócios, amigos e compadres que desempenham o papel social de construtores de todo capital financeiro com investimentos em vários setores da economia brasileira. $\mathrm{O}$ patriarca Guinle tem sete filhos 5 homens e 2 mulheres, o segundo filho Guilherme fica "incumbido" da missão de ampliar o patrimônio familiar e, além dos negócios adquire o status de filantropo e mecenas, sendo que aos demais filhos coube o deslumbre. Todo o glamour se refletiu em ciclos de amizade e atuação nas altas rodas sociais nacionais e internacionais com nomes na lista de chefes de Estado, personalidades cinematográficas, políticos, empresários, industriais e uma série de gente em destaque social político e econômico que influenciava a cena política e, também, o desenvolvimento do país. No crivo científico a atuação desse sobrenome para o cenário nacional foi fundamental no processo de modernização do Brasil, porém, denota uma dependência do capital financeiro internacional cujo início data do período Imperial essa foi a marca da atuação 
da burguesia, junto às benesses do governo ${ }^{4}$. É notório o fato de que tais representações foram a fonte de acúmulo de capital social, cultural, político e econômico em que pese o ônus social para os que se encontram fora desse ciclo. A proposta de investigar a classe dominante, tem seus desafios indo da escassez de informações ao impedimento da análise, uma vez que nem sempre documentos são disponibilizados é onde entra em cena a criatividade do pesquisador. Nessa produção a perspicácia dos autores foi fundamental para diagnosticar os comportamentos da elite. As relações pessoais com o governo foram de fundamental importância, para realizar mudanças estruturais. Os Guinle usam desse capital para firmar acordos, acumular capital, manter relações estratégicas desse modo efetivam as estruturas compatíveis exigida pelos países, cujos capitais, seriam investidos aqui. Desse modo, atende as exigências de um mercado internacional e se projetam nacional e internacionalmente.

Do ponto de vista da história inicial dos Guinle nomes como o de Cândido Gaffrée e de Linneo de Paula Machado são associados comercialmente e por apadrinha mento fazendo parte da família e dos negócios ${ }^{5}$. Essa história tem início com a concessão do porto de Santos posteriormente conhecido como Cia das Docas de Santos. Fato esse que abre as portas para uma pioneira infraestrutura de funcionamento do Brasil nos moldes das gradativas exigências do mercado ora inglês, ora canadense, ora norte americano, de modo que todo e qualquer ramo de atividade trouxe a marca Guinle na razão social e na característica do investimento ${ }^{6}$. A estratégia dos sócios passou pela vinculação dos mesmos ao Clube dos Engenheiros - locus de ampliação e solidificação de contatos com uma elite social que os levaria a fama e fortuna. Dentro da capital da época, o Rio de Janeiro, todo projeto encabeçado pelos sócios era frutífero, porém, a derrocada estava por vir. A era Vargas sempre foi de bons fluídos e intenso fluxo Guinle, mas um dia a capital mudou e tudo esfriou e acabou... O ponto alto da era Guinle ficou por conta da construção do Hotel Copacabana Palace e sua curiosa exigência da construção de um cassino. A derrocada ficou por conta da mudança da

\footnotetext{
${ }^{4}$ Em nossos dias, esse glamour custa caro aos cofres públicos saindo do bolso do contribuinte associado à mídia no processo de difusão dos valores de classe.

${ }^{5}$ É o comércio de tecidos o precursor de todos os outros investimentos, com a firma Gaffrée \& Guinle se lançam à construção de estradas de ferro e desencadeiam um aumento significativo do seu capital econômico.

${ }^{6}$ Os investimentos variavam da agricultura a energia elétrica, do comércio de tecidos a ferrovias, da efetivação da energia elétrica a produção de café ou da telefonia a hotelaria. Todas as áreas de funcionamento da cidade dependiam da assinatura dos Guinle.
} 
capital para Brasília e junto com ela todo circulo decisório do qual a família desfrutava por meio de relações pessoais e privilégios.

No terceiro capítulo, novas características da realidade nacional são apresentadas destacando-se a análise do perfil do sobrenome Simonsen sob aspectos de sua liderança e pioneirismo no rol do incentivo a industrialização do país. Empresário preocupado com vários aspectos da realidade brasileira Simonsen é engenheiro e participa do debate nacional nas décadas de 1920 a 1940 respondendo as inquietações de seu tempo com a industrialização que entende como fundamental para o desenvolvimento econômico, social e cultural do Brasil. Entendia como um grande entrave o desconhecimento sobre a realidade nacional da sociedade como um todo e em combate a esse mau, na condição de empresário industrial paulista, desenvolveu um projeto de hegemonia política no decorrer dos anos trinta cujo momento inaugural acontece com o discurso de Simonsen na fundação CIESP em 1928. Nesta ocasião, defende a complementariedade entre indústria e agricultura, entendendo de modo particular a hegemonia como sendo da indústria. Defende que o Estado deve ajudar o capital privado e intervir com moderação na economia. Assume seu primeiro cargo como engenheiro Chefe da comissão de Melhoramento de Santos e tem um currículo beneficiado pela sua condição de classe, bem como os cargos que assume até seu ápice quando é engenheiro na Brazilian Railway onde efetivamente vincula sua carreira ao desenvolvimento econômico do país. Trabalhou para efetivar seu projeto de industrialização fomentando a profissionalização numa perspectiva técnica com o objetivo de facilitar o financiamento do capital estrangeiro. Compondo a vanguarda de uma nova elite técnica deu corpo ao seu projeto de industrialização junto aos governos, desenvolvendo a ideia da profissionalização do trabalhador ${ }^{7}$ defendia uma racionalidade técnica, demonstrava forte influência taylorista.

Tem uma carreira que se inicia no topo, por herança de um capital familiar que lhe conferiu bom fluxo social, econômico e político. Cursa Engenharia nas melhores escolas e antes mesmo de terminar seu curso já atua na área como profissional sendo que o ponto alto da sua carreira está na concessão da construção dos quartéis para o exército brasileiro e que lhe permite viajar o Brasil e viver de perto a realidade brasileira, outro aspecto importante na execução desse projeto foi a representatividade

\footnotetext{
${ }^{7}$ Nessa perspectiva, havendo um aumento da qualidade profissional, além de oportunizar a educação desse trabalhador, seria possível demonstrar aos possíveis investidores internacionais que valia a pena o investimento no país.
} 
de uma classe profissional que emergia no período do regime militar, qual seja os engenheiros que passam a ganhar notoriedade pela atividade que desenvolvem. No país em desenvolvimento foi a categoria profissional que, se convencionou, ter a capacidade de dirigir não só obras públicas como administrar algumas estatais ${ }^{8}$ sinalizando o surgimento de uma tecnocracia.

No quarto capítulo o imaginário é estimulado num universo de poder, riqueza e oportunidades junto ao governo e aos círculos empresariais com o sobrenome Klabim e Lafer. Um sobrenome que surge com o comércio madeireiro em 1885 na Lituânia e em função da restrição, imposta pelo czar Alexandre III, quanto a aquisição de propriedade por judeus o patriarca Maurício Klabin foge para a Inglaterra, acrescenta ao seu nome do meio Freeman e, em 1889, com 29 anos, desembarca no porto de Santos vindo em busca de melhores oportunidades e reconstrução de sua vida encontrando um campo fértil aqui onde livremente pode exercer suas atividades comerciais. E, da tipografia à fábrica de papel juntamente com seus irmãos Salomão e Hessel e primo Miguel Lafer fundam a Klabin Irmãos e Cia - KIC. Desenvolvem atividades comerciais que atendem aos centros urbanos ${ }^{9}$ em franco desenvolvimento por conta das mudanças que estavam ocorrendo no país em função das ações transformadoras dos sobrenomes anteriormente citados. Logo tratam de se organizar e montar associações de classe para unidos se aproximarem do processo decisório com uma representação significativa articulando projetos e medidas para proteger seus negócios sob a égide do crescimento econômico e como compensação pelos altos investimentos praticados pelo grupo ${ }^{10}$. Os empresários organizam então o Centro das Indústrias do Estado de São Paulo - CIESP que é presidido por Francisco Matarazzo e tem como um dos presidentes Horácio Lafer o que denota a mobilização da burguesia na formação de seus intelectuais, bem aos moldes descritos por Gramsci, são eles que vão exigir representatividade junto aos órgãos do governo seja aprovando leis seja recebendo concessões monetárias do erário público. Esses agentes políticos concentram-se nesse campo político e legislam em benefício

\footnotetext{
${ }^{8}$ Estevinho, Glória ao estudar a prosopografia do BNDES observa que também na presidência desta estatal o primeiro cargo a ser ocupado por Ari Francisco Torres um engenheiro. Trabalho apresentado no VII Seminário Nacional de Sociologia \&Política na UFPR em 2017 com o título de: Prosopografia dos diretores do BNDES (1952-2016) e publicado pela revista NEP- DOI: http://dx.doi.org/10.5380/nep.v3i1

${ }^{9}$ Iniciam suas atividades com material de papelaria e escritório, o que era um mercado crescente, uma vez que tudo caminhava para a efetivação do processo de industrialização no país.

${ }^{10}$ A estratégia utilizada pelos donos do capital era a criação de uma associação de classe, assim como no caso dos Simonsen o clube dos engenheiros...
} 
próprio aumentando seus capitais e solidificando sua atuação governamental, infiltramse para dominar o Estado uma vez que seus capitais são herdados.

E é da Colônia Santo Ângelo, no Rio Grande do Sul, que se projeta o sobrenome Gerdau - Johannpeter, oriundos das margens do rio Elba a oeste de Hamburgo Johannes Henrich Kaspar Gerdau chega ao Brasil, numa geração de imigrantes, alemães que trazem como capital cultural uma formação técnica, no caso, contabilidade, de origem urbana, pois sai de uma região portuária e industrializada diferente dos demais desta colônia. Aqui adota o nome de João Gerdau e dá início a uma trajetória de acumulo de capital político econômico e social. Inicialmente como comerciante tem rápido crescimento econômico na colônia alemã que ajudou a formar e tem a oportunidade de girar esse capital fornecendo produtos à corte no Rio de Janeiro. Aproveita os bons fluídos do comércio local, expande seus negócios e atende ao mercado interno e externo com produtos como alimentos, vestuário e ferramentas promove na colônia, onde habita, um rápido crescimento econômico eleva seus ganhos de 6 a 11 contos de réis elevando seu status dentro da colônia. Constituí família e traz do sul do rio Elba sua prima Alwine Marie Sophie Gerdau, nascida em Neuenfeld, zona rural de Hamburgo, mas com uma educação de elite. Ao chegar ao Brasil tem dificuldades de adaptação, especialmente após o nascimento dos seus dois filhos e a perda da sua filha Marta Alwine com 11 dias, por vírus da crupe. Em virtude da falta de estrutura, saúde e escola, pressiona o marido para mudar para um centro urbano, que fica inclinado a atende-la em função, também, das mudanças estruturais que acabam por abalar a autonomia da colônia. A fonte de informação de João Gerdau, que era a venda central, entra em desuso por conta das tecnologias de informação e transporte, o que o faz perder dinheiro. Muda-se para Cachoeira, onde a população e a infraestrutura são maiores. Tendo habilidades de multiplicar o capital tem nesta cidade um aumento considerável de capital e avança no sentido da diversificação, é o caso da Lei Geral de terras de 1850 que abre espaço para comercialização privada de terras com fins de colonização, de modo que João Gerdau, em parceria com os grandes proprietários de terra, finda uma companhia no armazém da colônia. Nesse momento, são ativadas suas habilidades de articulação e associação com os proprietários de terras, além da de gestão e vendas e surge um novo negócio que desenvolve com maestria. Esse ramo de atividade durou 10 anos e duplicou seu patrimônio sendo que 1893 estimava-se em 37,6 contos de réis. De pequeno comerciante a um status médio ocorre uma ampliação de 
capital culminado com a formação dos filhos e que o leva a buscar uma formação técnica em seu país de origem, de modo que, a segunda geração masculina cursa escola secundária em Düsseldorf, onde dispõe de um processo de industrialização avançada e prima pelo saber técnico, assim uma nova geração prepara seu futuro fora do Brasil sob tutela do tio Berthold. A mudança acompanha o Gerdau e, de Cachoeira muda o locus de atuação e viaja para Porto Alegre onde comanda uma empresa de comércio exterior trata-se da Gerdau \& Nachold do ramo atacadista especializado na comercialização de equipamentos e insumos para a produção de cerveja e outros bens. Essa sucessão de episódios comerciais forma gerações preocupadas com o capital econômico e com meios de garantir o capital cultural, mesmo que isso implique em estudar no exterior, via de regra a família buscou diversificar seu ramo de atividade. Coube as gerações futuras se infiltrar em outros ramos como educação, política e empresariais para garantir a perpetuação desse sobrenome. O capítulo descreve a formação de várias gerações Gerdau que constrói um capital cultural impregnado de valores étnico-classistas ao superar uma etapa do enriquecimento, amplia seus ramos de atividade e estende seus tentáculos a outros segmentos preocupando-se em prepar as futuras gerações de modo a reproduzir seus capitais. Passam da burguesia mercantil à burguesia industrial. Uma vez atuando em um segmento e obtendo bons resultados promovem o enraizamento em outros. Com o passar das gerações e, pela via dos casamentos, aumentam seus patrimônios e adquirem propriedades, criam bancos e atuam em comunidades beneficentes, como a preocupação dos fundadores era com a saúde educação, formam outras gerações com esses princípios estruturando novos campos. A associação ao capital estrangeiro é próprio do pensamento dos donos do capital e o fazem em nome do crescimento econômico, valendo-se do aparelho de Estado como extensão de suas fortunas.

No próximo capítulo, o autor apresentará alguns aspectos dos movimentos de exportação e de internacionalização do capital industrial protagonizado pelo sobrenome Bouças. Na figura de Valentim Fernandes Bouças, temos a apresentação de mais uma história de contribuição com a modernização do país através do uso da tecnologia no desenvolvimento de um equipamento pela Hollerith S.A. que domina o mercado dos cartões ponto em todos os órgãos públicos e onde haja funcionários que, no entendimento do empregador, precisa ser controlado em seus horários. Trata-se de um empresário paulista que, dentro dos processos modernizadores, da vinda das indústrias 
de base até as multinacionais, dado também abertura ao capital estrangeiro, é o responsável pela vinda da IBM ao Brasil ${ }^{11}$. A vinda desta multinacional é favorecida pelo exemplo de outros países que aqui já se haviam instalado, para os donos do capital era uma questão de internacionalizar seus capitais, sob a égide da modernização. Essa empresa traz um histórico de tecnologia condizente com os princípios aplicados à organização científica do trabalho, cujos equipamentos fabricados tem o objetivo do controle dos horários de entrada e saída dos trabalhadores, uma vez que seu carro chefe é o cartão ponto. O início das atividades vem da sua atuação como funcionário nas Docas de Santos onde estabelece uma rede de conhecimentos importante para desenvolver posteriormente sua trajetória a frente da Hollerith S.A., uma empresa de cunho familiar. Thomas J. Whatson, foi o conhecimento importante de que precisava para desenvolver toda sua história, pois ele era o contato com a IBM. Casa-se com Djanira thomas Coelho, filha de um general da marinha e acumula capitais sociais e políticos o suficiente para receber em 1920 elogios do Presidente Arthur Bernardes, ao referir-se a Hollerith no Congresso Nacional, fato esse que demonstra seu fluxo empresarial, volume de capital além de influência política. Sua fonte inesgotável de renda estava num contrato com o governo de instalação de suas máquinas em todo setor público e no fato de que tais equipamentos eram alugados. O que o leitor poderá desfrutar nesse capítulo é uma análise de época, uma visão panorâmica do Brasil político e econômico além de boas histórias sobre família, poder e dinheiro.

Ah, a comunicação! Como é importante saber se comunicar...tanto agora como outrora e dominar esse segmento, altamente rentável, não é para os fracos então eis que o capítulo trata do sobrenome Marinho, para o qual o autor reserva um breve relato histórico e expõe episódios que ilustram a influência política no país das organizações Globo. Foi Irineu Marinho, cuja carreira tem início como repórter e diretor do jornal Gazeta de Notícias; em 1911, que num primeiro momento funda o jornal A Noite administrando-o por cerca de 20 anos. É em 1925, com o Jornal O Globo, que dá início a história que é contada neste capítulo. Trata-se de uma família cujo acúmulo de capital

\footnotetext{
${ }^{11}$ Elencamos até aqui as discussões feitas nos capítulos e apresentadas pelos autores nas trajetórias dos Guinle e Gerdau, entre outros, um projeto de industrialização e crescimento econômico sempre vinculado ao capital estrangeiro. Esses sobrenomes protagonizam e reproduzem um olhar para fora do país e, por outro lado, maneiras de negociar via tutela do Estado. A classe dominante constituída, em sua maioria, por estrangeiros que em determinada época encontram morada em terras brasileiras está construindo relações internacionais e por não nutrir sentimento de nação por aqui cuida de seus interesses exibindo as possibilidades de lucro fácil ao capital internacional. A elite nutre um sentimento exógeno pelo Brasil desde o Império.
} 
encontra-se na casa dos bilhões compondo o ranking de uma das famílias mais ricas do país, segundo a Forbes 2014. Na década de 1970 é criada a FRM - Fundação Roberto Marinho, a qual tem o benefício da isenção de impostos por tratar-se de uma empresa "sem fins lucrativos", e seguem o baile, atrás de ações voltadas para o "social" escondendo vários outras empresas a ela vinculadas que vão de programas educativos a vários empreendimentos de capital nacional e internacional, sendo que seu carro chefe são os meios de comunicação. Sua postura de imparcial e de "defesa das causas populares" na prática age em defesa desde os governos militares a golpes e políticas neoliberais, ainda hoje manipulando informações sempre em defesa dos interesses capitalistas. Ganhou status de entretenimento, lazer, chegando a ser a única fonte de informação, devido aos altos índices de audiência com o JN - Jornal Nacional, foi também num crescente creche, trabalho e cidadania manipulada. Defensora da "liberdade de empresa" muito mais do que a da imprensa, devido a sua ojeriza às críticas... Capítulo interessante para desmistificar a mídia e sua repercussão na atualidade, como formadora de opinião.

Os capítulos anteriores fizeram referência a organizações de classe especialmente as que aludiam a tecnocracia nascente na figura dos engenheiros, pois bem, o capítulo que segue demonstra o quanto esse pensamento é atual e marca um rol de oportunidades na área da construção civil. Apresenta os sobrenomes dos donos do capital cujas matérias estampam os jornais, especialmente no caso da Lava -Jato, onde as empreiteiras são citadas, uma série na saga das empreiteiras no Brasil. Estamos falando de sobrenomes como os Camargo Correia, Andrade Vieira e Oldebrecht em seus casos de família. Esses capitais familiares buscam pela via matrimonial aumentar seus patrimônios e se infiltrar em órgãos públicos, adotando a prática de desprezar o capital nacional, relegado a um segundo plano, e tem como a chave de todo sucesso as associações propostas pelo governo, então crescer depende muito da hora certa e do lugar certo. Seus objetivos são os das concessões públicas, visando o mercado das licitações e o internacional sempre desfrutando das benesses do governo e de suas agências. $\mathrm{O}$ autor vai traçar o início da construção dos patrimônios familiares e segue com uma relação de capitais sociais alinhavando suas participações no aparelho de Estado culminando com aumento de patrimônio desenhando um quadro de influências no processo decisório. Entre as influências citadas está um forte vínculo pessoal e parental entre o presidente desde Getúlio Vargas e cuja influência perdura até Juscelino 
Kubitischek, o que o mantêm na liderança no ranking licitatório. Para a Oledebrecht coube o amargor da $10^{a}$ posição até a chegada de Ernesto Geisel que marca a virada dessa posição. As notícias de escândalo marcam as três empreiteiras bem como a participação do BNDES nas irregularidades, e o desvio do dinheiro público.

E o penúltimo capítulo fica reservado aos bancos trazendo em seu conteúdo poder, política e negócios assinando com os sobrenomes: Moreira Salles, Setúbal e Villela. Com Moreira Salles muitas descobertas serão feitas sobre o mundo das finanças, o leitor vai presenciar a transformação do capital oriundo dos negócios do café que vai desembocar na criação do UNIBANCO, seguindo uma jornada de criação de bancos por todo o país. Corre a boca miúda que: "O amor é produto de quanto se tem no bolso" se isso procede não sei, mas analisando as ligações amorosas de Moreira Salles podemos ver 3 enlaces significativos que deixam herança em alguns segmentos da vida social a saber cinema, editora, banco. Em suas primeiras núpcias a escolhida foi a filha de um alto executivo da indústria de perfumaria, a segunda com uma socialite cujas recepções ficaram famosas por receber altos executivos internacionais e outras personalidades. Essas uniões geraram frutos que se encontram, ainda hoje, atuando em grandes empresas familiares.

E diretamente do Maranhão nos é contada a história do sobrenome Sarney, que era nome e agora é a marca registrada dos locais por onde se anda no Estado. Também na política, esse sobrenome impera e já foi liderança por fatalidade da Nação exatamente quando assume como vice presidente a presidência por conta da morte de Tancredo Neves.

Minha modesta sugestão para a leitura dessa obra deve-se ao fato de que o leitor vai desfrutar de muita informação importante com dados históricos importantíssimos sobre a formação do Brasil. Vai encontrar excelentes profissionais preocupados com o trabalho científico e uma análise comprometida com a verdade dos fatos. Boa Leitura! 